\title{
Pairing flavours and the temporal order of tasting
}

\author{
Charles Spence $^{1 *}\left(\mathbb{D}\right.$, Qian Janice Wang ${ }^{1}$ and Jozef Youssef ${ }^{2}$
}

\begin{abstract}
There can be little doubt that plating food beautifully is becoming ever more important in the world of high-end cuisine. However, there is a very real danger that all the attention to how a dish looks (or photographs) can end up obscuring the importance of temporal order to flavour perception. That is, there is an increasing tendency to prioritize plating elements in a dish so that they please the eyes of the beholder, rather than necessarily because they deliver the optimum balance of sensations to the palate. Relevant here is the fact that certain combinations of ingredients taste better when sampled simultaneously, or in a particular sequence, than when sampled in a different order. In this review, we examine the importance of sequencing and pairing taste/flavour sensations, both in the design of the meal itself, and when attempting to combine (or match) food and drink. We address the chemical, psychological, and computational strategies that have been suggested by those wishing to combine flavours for maximal impact. We evaluate three general principles of flavour matching: similarity—matching components based on common flavour compounds (or similar flavour profiles); contrast—combinations that are purposely chosen because they differ from each other (a strategy that is more common in the cuisine of some countries than others); and synergy (or emergence) - those combinations that together deliver new flavour experiences or else harmonize with one another. We argue that the psychological account (informed by an awareness of cultural differences), and to a lesser extent the chemical account, provides meaningful suggestions as far as effectively combining flavours is concerned.
\end{abstract}

Keywords: Taste, Flavour, Pairing, Similarity, Contrast, Harmonization, Emergence, Computational gastronomy

\section{Review} Introduction

The two Michelin-starred chef, Denis Martin, used to serve an intriguing dish in his namesake restaurant in Vevey, Switzerland (see Fig. 1). It came to the table on a spoon, and in a single mouthful, the attentive diner would experience a sequence of distinctive flavours/ mouthfeels, each revealing themselves one after the other. First came the sharp "hit" of wasabi, then the tender texture of the tuna itself, and, finally, the slow creamy melting mouthfeel of the white chocolate. (The dish itself contains raw tuna, white chocolate, raw Thai chilli, toasted peanut oil, wasabi, and a pinch of fleur de sel; see [1], pp. 82-83). It can be argued that part of the pleasure of this dish was the very temporal evolution of the distinctive mouthfeel/flavour experiences. Had the

\footnotetext{
*Correspondence: charles.spence@psy.ox.ac.uk

'Department of Experimental Psychology, University of Oxford, Oxford OX1 3UD, UK

Full list of author information is available at the end of the article
}

various ingredients simply been mixed together, the diner's experience would likely have been quite different (see [2-6], on the temporal ordering of taste and odour mixtures).

Much the same idea (that there is pleasure in the dynamically changing sequence of tasting sensations) is hinted at in the following description of Heston Blumenthal's surprising Caviar and white chocolate disc combination: "To serve, spoon some caviar (about half a coffee spoon) on top of the disc, and eat. You can experiment with the quantity of caviar, depending on your taste. The sensation of these sweets is heightened if you place the chocolate and caviar disc on the tongue, close your mouth and leave to melt. As the chocolate melts, the caviar flavour comes through gradually. You will be amazed by the pleasure of the changing flavours and sensations." (quote from [7]). Once again, it is the changing sequence of flavours and mouth sensations that is deemed to be so pleasurable. 


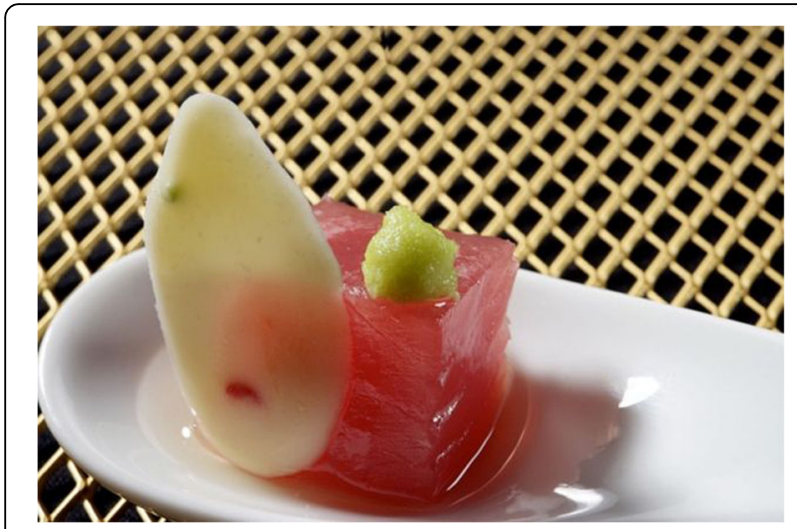

Fig. 1 The Thon au chocolat blanc et piment Thaï dish served at Denis Martin's namesake restaurant in Vevey, Switzerland (http:// www.denismartin.ch/; [1]). A dish to be consumed in a single mouthful, thereby delivering a distinctive series of flavour

experiences, extended over time (but, importantly, under the control of the chef). [Picture from http://www.cavesa.ch/blog/wp-content/ uploads/archives/b/bl/blog.cavesa.ch/aoctobre/thonlivre10_small.JPG. Author: Denis Martin]

In terms of sequencing tasting experiences during more mundane food encounters, there may well be a relevant link here to Hyde and Witherly's [8] notion of "dynamic contrast," defined as "moment-to-moment sensory contrast from the everchanging properties of foods manipulated in the mouth." Focusing on everyday foods such as ice cream, these researchers argue that dynamic contrast during consumption, typically somatosensory contrast, such as the temperature change when consuming a spoonful of ice cream or the textural changes when eating a piece of chocolate or masticating a crunchy food such as a potato chip is especially rewarding-that is, we find it particularly palatable. They hypothesize that it is just such dynamic contrast that is such a distinctive feature of ice cream (together with its cooling/refreshing nature) that explains its place as the final course on the menu, at a time when many diners might well say that they are already full. This they call the "ice-cream effect." There is probably also a link to the recently introduced notion of "hedonic escalation" [9]. This term describes the increased liking of each additional bite of a palatable food that contains multiple identifiable flavours that are revealed successively (we return to a fuller discussion of the notion of hedonic escalation later).

It should come as little surprise to find that many top chefs are increasingly starting to consider how exactly the diners interact with their dishes. After all, even if the food on every plate is the same, the order in which the diner samples the various elements may fundamentally change the ensuing experience. Certainly, all the talk of precision cooking in the world of molecular gastronomy would seem to imply that exact control over the tasting experience ought to be important (see $[10,11])$. That said, while some chefs work hard to control the temporal order and dynamic changes in the tasting experiences that they deliver, others would seem to go to the other extreme and deliberately give up as far as controlling the sequence of tasting is concerned.

Chef Andoni of Mugaritz in San Sebastian is interesting on this theme. Just take the following description of one of the dishes served at the restaurant: "The dish 'Roasted and raw vegetables, wild and cultivated shoots and leaves', ... consists of hundreds of vegetables, leaves and herbs - something nobody would think of trying at home. One hundred ingredients make it impossible for the person preparing the dish to plate any two in the same way. It also makes it almost impossible for two diners to eat it in exactly the same way. This is one of the evocative powers of this recipe." ([12], p. 42). In this case, it would appear that the chef has designed the dish in light of the awareness that they cannot control how the diner will eat it.

In the three fine-dining examples mentioned so far, we are undoubtedly talking about the very high end of modernist cuisine. It is important to note that this situation might be in some sense special, given the diner's likely mindset in such a venue to want to search out different flavour experiences with each consecutive mouthful (see [9]). More generally, one might ask how important it is to get the timing and sequence of flavour sensations within a dish "right" during more regular everyday consumption episodes. Is it enough simply to plate "for the eye" as the Roman gourmand Apicius [13] would have us believe (see also [14])? Thinking about this, and properly designing the sequence of flavour experiences, is a topic that is becoming increasingly important. Many chefs are becoming ever more obsessed with the eye appeal of the dishes they prepare (see [15, 16], for reviews). At the same time, diners often want to choose the sequence in which they taste the various elements in a dish (see Fig. 2 for one such colourful example). Of course, one might argue that it is often actually the chefs who are happy to leave the temporal ordering of tasting, and taste sensations, in the hands of their diners.

In any case, perhaps it can be argued that for much of the time, the order in which flavours, and the various components of a dish, are sampled, and hence experienced, does not significantly impact the final flavour experience. The corollary of such a view, if correct, being that the chefs can continue plating for the eye without worrying too much about the sequence in which the flavours they create on the plate happen to be experienced. After all, with a mouthful of food and drink, how does 


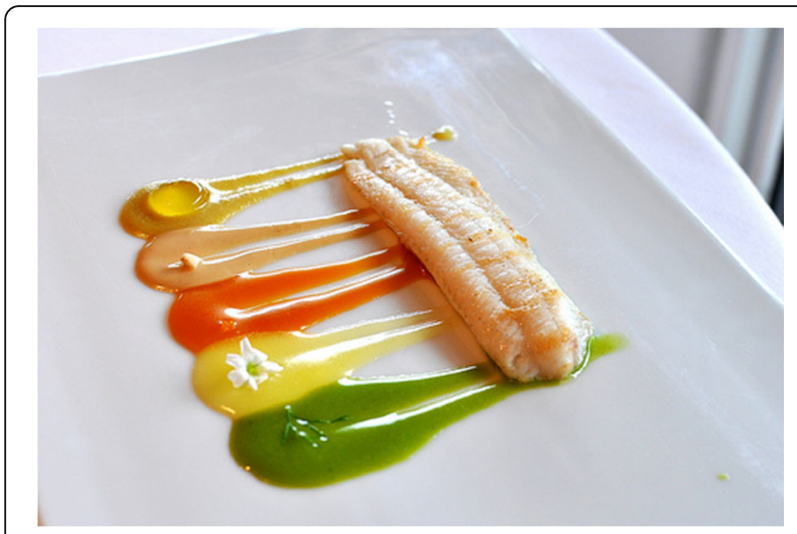

Fig. 2 The Sole, Olive Oil, and Mediterranean Flavors dish served at the El Cellar de Can Roca restaurant in Girona, Spain (http:// cellercanroca.com/index.htm). Simultaneously plating for the eye and, at the same time, allowing/encouraging the diner to explore the various flavour combinations in the dish. (Notice also the disambiguation of the meaning of the colours through the use of flowers, etc. in each of the sauces; see [94]) [Image from http:// gastronomyblog.com/2010/08/14/el-celler-de-can-roca-girona/; Photo credit: HYPERLINK "http://gastronomyblog.com" GastronomyBlog.com]

one really know what to bind together and what to keep separate? Once we break food down and mix it up in the mouth, when all texture cues have gone, what is left in terms of distinctive elements in the tasting experience?

In this review, we argue that getting the order of mouth sensations right is important, at least for certain combinations of ingredients/flavours. We will start by illustrating what not to do in terms of sequencing tasting experiences with a few classic everyday examples. Having analysed these "worst-case" scenarios, we will then be in a much better position to address what to do when it comes to trying to optimize the diner's multisensory tasting experience. We will review chemical, psychological, and the (newly emerging) computational gastronomy approaches to the problem of effective flavour combination. We will then look at the various strategies that have been put forward over the years in order to accentuate, contrast, or harmonize flavours ([17], p. 26). All of these strategies have been suggested at some point in print, regardless of whether one is talking about the various elements that might be combined together in a dish, or when trying to optimize food and drink (e.g. wine or beer) pairings.

One of the tensions that will be highlighted in this literature review relates to the widespread assumption that those foods that share flavour compounds will pair well together. For contrary to what many who are interested in computational gastronomy would have us believe, the fact that a selection of ingredients share some number of flavour compounds is certainly no guarantee that they will necessarily combine well, perceptually speaking, in the mind of the diner (see $[17,18]$, for contrasting perspectives on this theme). As we will see later, multisensory flavour perception turns out to be much more complex, and culturally determined, than some commentators would seem to realize.

\section{Some classic combinations to avoid Red wine and seafood}

Traditionally, certain food-wine combinations were thought to be best avoided, such as red wine with seafood (e.g. [19]). For, while both may taste wonderful on their own, when combined, diners would often be left with a rather unpleasant sensation. Reports of a ferrous taste, an unpleasant fishy and/or metallic odour, and possibly also bitterness in the mouth are not uncommon [20]. Intriguingly, the latest research has identified that it is the ferrous ion in some red wines that gives rise to the unpleasant fishy aftertaste [21].

In an elegant series of studies, Tamura et al. demonstrated that it was the concentration of total iron and of ferrous ion in red wine (not the phenolic tannins that some had suspected to be responsible) that correlated with reports of a fishy aftertaste when participants were given samples of dried scallop to evaluate. Chelating the ferrous ion in the wine reduced reports of the unpleasant fishy aftertaste when paired with the scallops. By contrast, adding ferrous sulphate to a model wine increased such reports. The researchers suggested that it was the potent volatile compounds such as hexanal and heptanal that are formed (by the combination of dried scallop and red wine) and that were responsible for the unpleasant sensations in this case. (Interestingly, though, this potential clash is less likely to occur nowadays given the change from iron to steel in wine-making. It was the former that would result in much of the ferrous matter making its way into the wine; see [22].)

On the flip side, in terms of good food and wine matches, one oft-made recommendation is to pair red wine with meat while pairing white wine with fish. This suggestion can be explained, at least in part, by interactions taking place between components that are found in the wine and in the food. So, for instance, the food proteins in meat are thought to reduce the bitterness and astringency of tannic red wine. They may also help to alleviate the sourness and astringency of a dry white wine (see [23]). Other combinations that have been recommended, so far on the basis of personal opinion rather than any obvious evidential footing, include sherry and dry white wine with kippers and mackerel [20,24]. Note here that highly acidic wines have iron chelating properties, while both fino and manzanilla sherries have a relatively low ferrous ion concentration [21]. 


\section{Orange juice after toothpaste}

Many of us have had the unpleasant experience of drinking orange juice that tastes exceedingly bitter, not sweet, after having just brushed our teeth (e.g. see https:// www.youtube.com/watch?v=9X5_gtel-c0; $[25,26])$. In this case, it is the sodium lauryl sulphate (SLS), a detergent added to many toothpastes, that blocks the sweet taste receptors in the mouth. SLS apparently also destroys the phospholipids that inhibit bitter taste perception. Of course, eating an orange before washing your teeth does not have anything like the same effect-that is, this is a case where the temporal ordering of sensations really does matter (about which, more later).

Notice how in the first of the above-mentioned examples, it is the chemical reaction between components of the two substances that is best avoided. In the orange juice case, by contrast, it is the change in sensitivity of a subset of gustatory receptors in the oral cavity that then changes how a subsequently tasted food is perceived. These can be thought of as chemical and physiological accounts, respectively, for why certain combinations of oral sensations just do not work together. And while the toothpaste example might not seem especially relevant to the restaurant setting, bear in mind here only that there are a number of other ingredients that also suppress various aspects of taste perception. In fact, anything that irritates/stimulates the trigeminal nerve, such as chilli and menthol, will probably have just such an effect, though the literature suggests that this kind of cross-sensory interference may be restricted to the perception of sweetness (e.g. see $[27,28]$ ). (No one, after all, would think of serving a mint before dinner, would they?)

So, for example, miracle fruit (miraculin, derived from berries of the West African plant synsepalum dulcificum; [29]) is known to suppress the sour receptors and hence make whatever is tasted for an hour or so thereafter seem much sweeter than normal (e.g. a slice of lemon will taste sickly sweet; see [25, 30-32]). Miraculin is thought to attach itself to the taste receptors on the tongue [33]. When a person subsequently bites into a slice of lemon, lime, or perhaps a packet of salt and vinegar crisps, the $\mathrm{pH}$ in their mouth drops, and somehow (though researchers are still uncertain quite how), the sweet receptors are activated. Relevant here, miracle berry pills have featured on the menu at some high-end modernist restaurants (see [34]), though always as pretty much the last thing that the diner is given to taste. Meanwhile, gymnemic acid, which can be found in the leaves of the tropical plant (Gymnema sylvestre), depresses the perceived sweetness of foods. So, for example, Eisner and Halpern [31] have reported that an orange eaten after chewing on Gymnema leaves will tastes like lemon or lime.
The slow-developing, yet relatively long-lasting oral tingle that one gets on contact with the Szechuan peppercorn or flower (in this case triggered by the presence of the hydroxy-alpha-sanshool molecule) presumably raises similar issues around the ordering of taste sensations within a meal (e.g. see [35]). Szechuan peppercorns are a commonly used ingredient in regional Chinese cuisine. Finally here, another relatively common example of a sequential effect on tasting occurs when water tastes sweet after eating globe artichoke (see [3638]). In this case, it is a substance known as cynarin that latches onto the sweet receptors without activating them. Nothing happens until a person drinks water, at which point the cynarin molecules are washed away, thus releasing the receptors and triggering a sweet percept in roughly $60 \%$ of those tested by Blakeslees [37]. It has also been reported that artichoke can modify the taste of wine, making it appear sweeter to some people (e.g. [39-41]).

Finally, in this section, one other more mundane sequence to avoid can be illustrated by thinking about something like eating a slice of chocolate cake, say, followed by the taste of a drink of hot chocolate. The latter is likely to lack flavour, probably tasting more like warm milk instead. Tasting the cake and sauce the other way around is, we would argue, less of an issue. One might be able to explain this asymmetry in terms of one ordering of these similarly flavoured stimuli giving rise to more dynamic contrast than the other way round (see [8]).

\section{Olfactory adaptation}

Sometimes, a combination of flavours may work especially well together (or not), due to the effects of adaptation. Olfactory adaptation can be defined here as a temporary, normal inability to distinguish a particular odour after prolonged exposure to that airborne compound (e.g. Cometto-Muñiz \& Cain, [42]; see also $[43,44])$. The notion that by adapting to a flavour compound in one item (be it the food or drink), another flavour may be experienced differently was elegantly captured in a dish trialled by the chef Heston Blumenthal a few years ago ([45], pp. 232-237; see Fig. 3). A two-flavoured cinnamon/vanilla ice cream was presented together with two squeeze bottles, one containing sticks of cinnamon and the other a vanilla pod. The idea here was that simply by sniffing one of the bottles for a few seconds, the nose/brain would start to adapt to the aroma contained within. Hence, when the ice cream is actually sampled, it should taste more strongly of the other flavour. If one repeats the procedure, this time sniffing the other bottle first, then the apparent flavour of the ice cream may well switch in the other direction. While the dish itself has more of a novelty-value feel to 


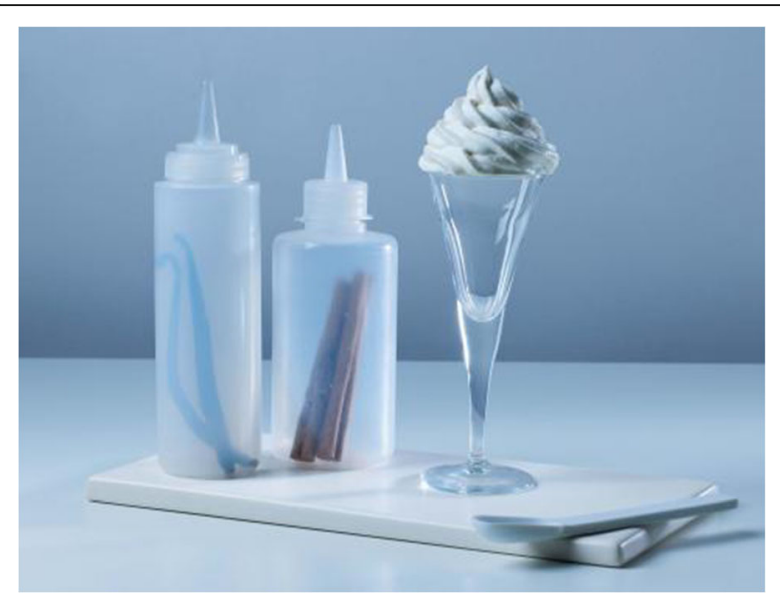

Fig. 3 Two-flavoured (cinnamon and vanilla) ice cream by Heston Blumenthal. Sniffing and hence adapting to the smell of either spice apparently changes the perceived flavour of the cinnamon-vanilla ice cream for about $85 \%$ of people [Image from http://sageappliancesclub. co.uk/article/cinnamon-and-vanilla-ice-cream; Photo credit: Angela Moore, Bloomsbury's Heston at Home]

it than anything else-as Heston Blumenthal himself puts it: "The cinnamon/vanilla milkshake still has the look of an eating experiment rather than an eating experience. Until I can change that, it stays off the menu." ([45], p. 237) - it nevertheless beautifully illustrates the principle that might help explain the success of at least some food-wine pairings. ${ }^{1}$ That said, a systematic analysis of the approach and of the role of adaptation definitely awaits further study. One of the challenges with conducting research in this area being the role of contextual and sequential effects on people's tasting judgments (e.g. see $[46,47])$.

It turns out that combining flavours, as when pairing food and wine, may affect one component of the tasting experience more than the other. A recent study illustrating this point involved the analysis of multi-bite wine and cheese combinations using the increasingly popular temporal dominance of sensations (TDS) technique. The participants tasted Pacherenc, Sancerre, Bourgogne, and Madiran wines after nibbling on epoisses, comte, Roquefort, and crottin de chavignol cheeses. Amongst other things, the results of this research revealed that cheese was more apt to alter the flavour of wine (increasing fruitiness ratings for the Bourgogne and Madiran wines), than vice versa $[48,49]$. In this case, wine and cheese pairings might be seen as a way to enhance or decrease specific sensory properties in a wine, rather than the wine necessarily being used to affect the cheese-tasting experience. Importantly, eating the cheese helped reduce the perceived astringency of the subsequently tasted wine (see also [46, 50-52]).

So, having taken a look at a number of the classic combinations to avoid when pairing tasting experiences, and having considered the role of short-term adaptation in multisensory flavour perception, let us now take a look at some of the strategies for effective flavour pairing that have been suggested over the years.

\section{Flavour combination strategies}

Eschevins [53] interviewed 20 sommeliers and beer experts in order to assess their recommendations concerning the pairing of two wines and two beers. An analysis of their responses revealed three main principles of flavour pairing-perceptual (harmonizing the dish as a whole or enhancing specific sensory properties), conceptual (pairing by tradition or by region), and individual (based on the diners' own personal preferences and experiences). Interestingly, wine and food matches tended to obey the conceptual principle whereas beer matches tended to focus more on personal liking.

There is, in fact, a long-established art to pairing wine with food, with scientist Francoise Chartier, one of the best-known researchers working in this space. Chartier ([17], p. 211) describes what he does as molecular sommellerie, defining it as: "the practice of developing food pairings and food and wine pairings based on dominant aromatic compounds" (see also $[18,54-56]) .^{2}$ Over the years, people have adopted a number of different pairing strategies: One suggestion here being to pick those combinations of ingredients/flavours that are either similar to, or contrast with, one another. Another strategy involves picking those combinations of flavours that harmonize, possibly giving rise to new flavour sensations in the process (see [57]).

When talking about similarity, though, the question soon becomes one of whether it is chemical similarity (i.e. shared flavour compounds) that matters or else perceived similarity (psychologically speaking; see [58, 59]) that we are talking about. Some commentators would appear to believe that one is, in fact, reducible to the other. However, the critical point to stress here is that food and/or drink combinations that share flavour compounds need not necessarily be rated as perceptually similar. Furthermore, it is worth bearing in mind that co-exposure - that is, the regular pairing of aroma with a taste in the food we eat-can lead to an increase in perceived similarity without having any impact on chemical similarity (e.g. [58, 60-62]). Aromas may take on the taste qualities of the foods that they have been associated with previously. For instance, most Westerners will rate the aroma of vanilla as sweet, not because the spice is itself sweet (it is not, anyone who has bitten into a vanilla pod will know just how bitter it is) but rather because in many Western cuisines, it is paired with sweettasting foods (such as cola and ice cream; [58]).

Blank and Mattes [58] had 70 North American adults rate the perceived similarity of 10 spices (salt and sugar 
granules, vanilla and anise extract, dried bay leaf, dried crushed spearmint leaves, ground nutmeg, ground cloves, ground cinnamon, and ground ginger), which they first smelled and then tasted. The intensity of the odour, its compatibility with sweetness, and the bitter taste were the three major characteristics that participants used to arrive at their similarity judgments. Unsurprisingly, vanilla was rated as most compatible with sweetness. Intriguingly, these researchers also reported some individual differences, with the nonwhite participants tested attributing a greater degree of sweetness to nutmeg and less sweetness to anise than their white counterparts (see also [63]).

Here, in passing, it is worth noting that the topic of innovative food/flavour pairing has become increasingly important recently due to the growing accessibility to foreign ingredients. For most of our time here on earth, recipes were developed based on ingredients which were native to the land/culture. Consequently, most national cuisines have always had distinctive flavour profiles: Think Mexico-lime, coriander, and chilli; France-garlic, rosemary, and butter; etc. [64]. That is not to say, however, that new ingredients do not become incorporated quickly into a region's cuisine-think tomatoes in
Italy, potatoes in Germany, or chilli peppers in Thailand. Nowadays, there are simply so many "new" ingredients available that were not part of a country's traditional domestic culinary repertoire. Consequently, chefs and food/drink companies are increasingly looking for innovative new ways in which to combine the range of ingredients that they now have access to, especially given the interest of many consumers in fusion/exotic cuisines. Indeed, as Visser ([65], p. 124) presciently noted, when it comes to cuisine, the contemporary taste for novelty offers "a wonderful marketing milieu" (see also [34], Section 1.3).

\section{The computational gastronomy approach to pairing flavours}

The recently emerging field of computational gastronomy (e.g. [66-76]) is premised, at least in part, on the notion that one can make recommendations for novel, but purportedly successful, flavour pairings based on the identification of common flavour compounds (see Fig. 4). ${ }^{3}$ So, for example, it turns out that a chemical compound like acetal can be found in everything from apple and orange juice, through whiskey and beetroot [77]. Meanwhile, there are flavour compounds in

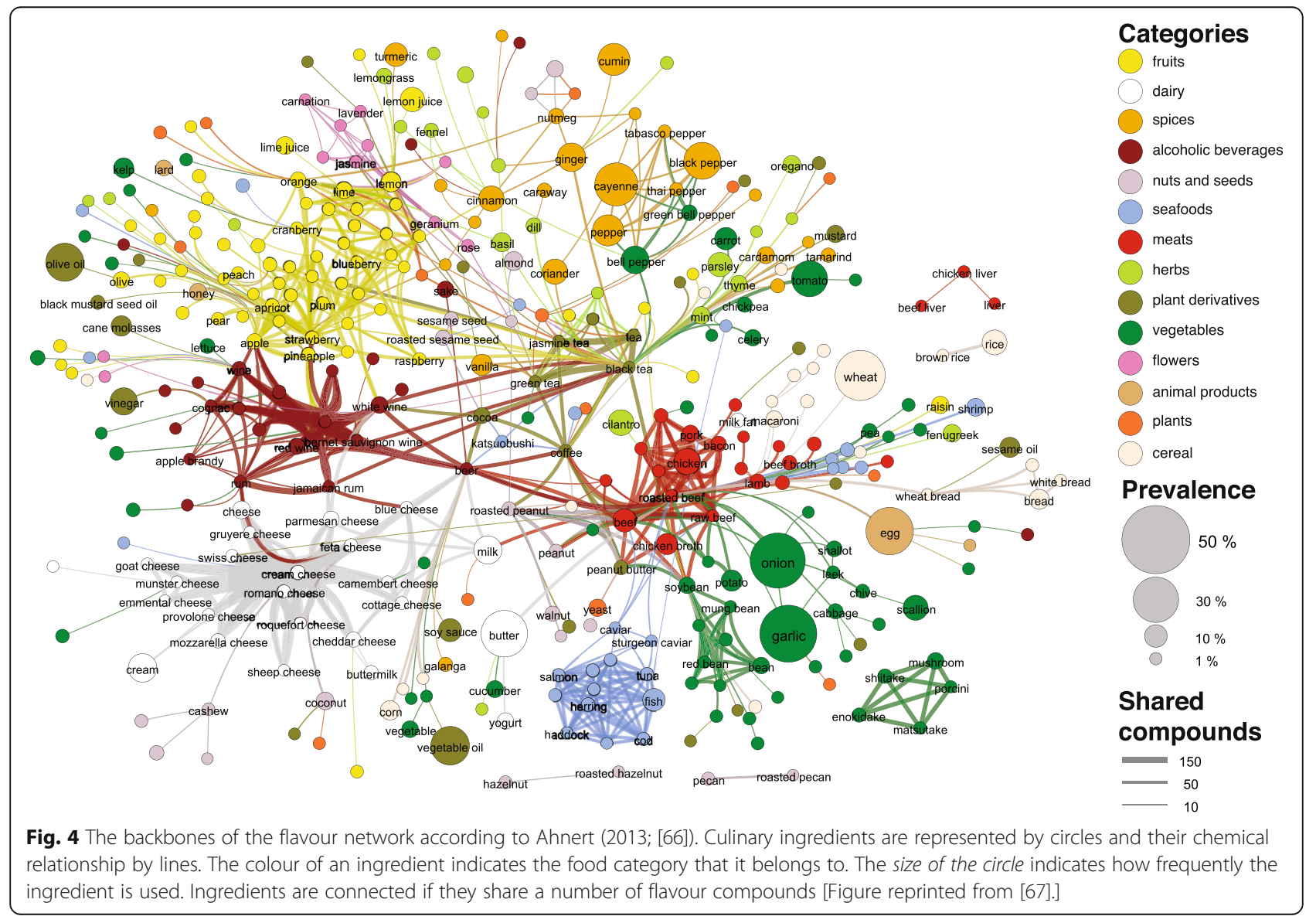


strawberries that one also finds in white wine. ${ }^{4}$ This approach, involving data mining and network analysis, now uses the large body of publically available recipes together with an understanding of flavour chemistry (see $[67,78]) .{ }^{5}$ According to Zolfaghifard [79], there are 381 ingredients in the world that are used for cooking, each containing an average of a little over 50 flavour compounds ([80]; with that value ranging from tens to hundreds of different flavour compounds per food ingredient; see Ahn et al., 2011).

Computational gastronomy builds on the food pairing hypothesis that: "If two ingredients share important flavour compounds, then they will go well together." (quote from [78]). Or take de Klepper's ([18], p. 55) slightly more nuanced definition: "The more aromatic compounds two foods have in common, the better they taste together. This effect is particularly strong when two foods share aromas that make up their characteristic flavour." World-famous chef Heston Blumenthal was initially a vocal proponent of molecular flavour pairing. As Ahnert ([67], p. 2) notes: "The chef Heston Blumenthal, together with flavour scientists has suggested that two foods that share chemical flavour compounds are more likely to taste good in combination [45]."

In the early days of interest in this new approach, combinations such as white chocolate and caviar, chocolate and blue cheese, and pork liver and jasmine were offered as surprisingly good, yet unusual, combinations that also happened to share flavour molecules ([7, 45], pp. 171172; [18]). White chocolate and caviar, for instance, both contain amines, while pork liver and jasmine share the volatile compound indole. Other popular combinations that share volatile compounds include salmon and liquorice, bananas and parsley, oysters and passion fruit, and garlic, coffee, and chocolate, the latter trio sharing the volatile compound 2-methylfuran-3-thiol [18].

However, despite Heston Blumenthal's initial enthusiasm, it is worth pointing out that the chef soon recognized the shortcomings of the flavour pairing approach. As he stated in an article that appeared in The Times newspaper in 2010: "Looking back at my younger self I'm almost embarrassed at my bumptious enthusiasm, not least because I now know that a molecule database is neither a shortcut to successful flavor combining nor a failsafe way of doing it Any foodstuff is made up of thousands of different molecules, that two ingredients have a compound in common is a slender justification for compatibility. If I'd known then what I know now, I would probably never have tried this method of flavor pairing: there are simply too many reasons for it not to work As it was, in my naivety I just got stuck in.” ([81], p. 45).

In a paper entitled "Food Pairing from the perspective of the 'Volatile Compounds in Food' Database," Miriam Kort et al. [82] put the Flavour Pairing Theory (see https://www.foodpairing.com/en/science-behind) to the test in an experiment with untrained participants. Importantly, however, no support for the theory was found. That is: "food pairings with more aroma overlap did not taste better than food pairings with less overlap. For example, chocolate and tomato (43\% overlap) did not taste better than cauliflower and pear (no overlap)." (quoted in [18], p. 58). de Klepper [18] continues: “...food pairing based on aromatic overlap is not a guaranteed recipe for success. Balancing flavors is what does the trick." (see also [83], for a similarly pessimistic take). So it would appear that flavour pairing is more useful to the chef as a tool for generating some novel ideas for ingredient combination rather than necessarily as a system for picking guaranteed winners [18]. As Blumenthal ([45], pp. 171-172) puts it: "I soon realised that the molecular profile of a single ingredient is so complex that even if it has several compounds in common with another, there are still as many reasons why they won't work together as reasons why they will... Molecular profiling is a great tool for creativity, but it supports intuition, imagination and emotion rather than replacing them."

There is a strong claim behind much of the computational gastronomy research. Just take the following quote from Jain et al. ([84], p. 3): "Molecular composition of food dictates the sensation of flavour [77]." It would obviously be nice for the computational gastronomist were such a claim to be proved correct. However, that is simply not the case: Just take coriander as an illustrative example-the population is genetically divided in terms of whether they perceive it as herby or soapy and hence pleasant or unpleasant (e.g. see [85]). One could make much the same argument about androstenone [86] and a number of other volatile compounds. In other words, there are a number of cases where molecular structure clearly does not dictate the exact flavour sensation.

When thinking about the practical implementation of the computational gastronomy approach, one also needs to factor in that the volatile compounds that are present in a food may change during cooking. Chartier ([17], p. 203), for instance, mentions the generation of new sapid molecules such as beta-ionone (with a fragrance of violets) when carrots are cooked (see also [87]). And as if that was not enough, one also needs to consider the influence of masking (just think about how salt masks bitterness while at the same time acting as a flavour enhancer; e.g. [45], pp. 232-237; [27, 88, 89]). And, as if that was not enough, there are some combinations of odorants that seem to give rise to the perception of a different odour quality (i.e. where the component odours are no longer identifiable; e.g. see [90]).

Also relevant here is the fact that what a key compound that gives one ingredient its distinctive flavour may well be barely noticeable in another, or else it may 
contribute to a different aroma profile, thus making it unidentifiable. Another potential problem relates to the perception of suprathreshold olfactory qualities. It has been known for many years that when the intensity of an olfactant changes, it can sometimes change the perceptual quality of the associated experience and not just the rated intensity (e.g. [91]). The computational gastronomy/flavour pairing approach also struggles with those flavour compounds where there are profound genetically determined perceptual differences. Finally, it should always be borne in mind that ingredients are not always incorporated into a recipe solely for the flavour they impart. Sometimes, they might be added to enhance the colour or change the texture of the final product.

In summary, the problem with the computational approach to flavour pairing, searching as it does for ingredients that share common chemical constituents, is that it simply does not work as a general principle. ${ }^{6}$ The approach neither guarantees nor does it necessarily predict many good unusual ingredient combinations. The main problem with this approach to flavour pairing, at least as it was originally formulated, is that it is based solely on shared compounds, without taking perceptual thresholds into consideration. Note here only that detection thresholds for certain compounds differ dramatically from one individual to the next [59]. And even if different ingredients share aroma compounds that does not guarantee that they will necessarily be present at a level that is detectable. One attempt to address this issue comes from focusing on the volatile compounds in food (as reported in [92]; see also [93]) that are shared, rather than merely focusing on the presence/absence of specific compounds (as captured by the Fenaroli database).

While it is certainly true that later attempts to develop the computational gastronomy approach based on the principle of flavour pairing do now tend to take perceptual thresholds into account, it is unclear how much success the approach actually has. For while proponents argue that, on average, the approach is likely to succeed at an abovechance level (and that the fact that some combinations that do share molecules do not pair well together does not prove that the approach, in general, does not work), those independent attempts to assess the approach do not appear to have met with much success. The latter negative assessment also seems to gel with the anecdotal reports of those chefs who have experimented with the approach.

\section{Chef Watson}

What should we say about IBM's Chef Watson (https:// www.ibmchefwatson.com/community)? On the one hand, one hears those working on the system suggesting that: "...we have developed a computational creativity system that can automatically or semi-automatically design and discover culinary recipes that are flavourful, novel, and perhaps healthy." (Varshney et al. [65, 94], p. 14). On the other hand, however, those who have tried Watson's bartending skills have not always been that impressed [95]. Watson makes suggestions based on an algorithm in which the system uses traditional pairings, regional pairings, flavour profiles, aroma (flavour) pairing, and learnt pairings from recipes developed by chefs who have used the system. A list of ingredients is then produced that is computed to work well together based on all of this information. Chef Watson has been described as a brilliant tool to exercise a chef's imagination and challenge them to use seemingly random, or at the very least unconventional, combinations of ingredients in dishes. However, it is important to note that it is still only pairing ingredients together and does not actually take final taste, flavour, or mouthfeel into account nor presumably the chemical transformations that might be induced by cooking. Ultimately, then, it is still the chef's responsibility to figure out how exactly to make something that actually tastes good and to develop recipes that really work.

\section{Cross-cultural aspects of flavour matching}

The latest computational gastronomy research has highlighted a cultural element to the way in which different flavours are combined. Specifically, the ingredients that co-occur in many Western cuisines tend to harmonize (that is, they share similar flavour compounds). By contrast, an analysis of more than 2500 online Indian cuisine recipes from [96] by researchers from the Indian Institute for Technology in Delhi revealed that ingredients tend to be combined in recipes (the average Indian dish contains seven ingredients) because they are dissimilar. This intriguing research revealed that ingredients with dissimilar flavour compounds were combined more frequently than would have been expected by chance (e.g. $[79,80,84])$. A similar trend toward combining ingredients with different flavour profiles has now been shown to be shared by the cuisine of a number of other Asian countries too [66]. ${ }^{7}$ For instance, Ahn and Ahnert [78] reported that an analysis of South Korean recipes also shared fewer compounds that expected if ingredients were combined randomly. This appears a much more productive direction for computational gastronomy approach than the flavour pairing route discussed earlier.

\section{Availability and habit as key determinants of the appropriateness of flavour pairing}

As mentioned already, there are, of course, examples of culturally appropriate (or recognized) flavour combinations that seem to have been based primarily on those particular combinations of ingredients that an individual has been exposed to previously ([64]; starting presumably in the womb, see $[97,98])$. As to why those particular elements should be combined, that is presumably 
partly explained by what is available in the region, just think of the traditional British combination of salmon with watercress (the latter, a common feature of the streams in which the salmon would have been found). This notion of combination based solely on coavailability is also captured by the phrase "What grows together goes together," ${ }^{\prime \prime}$ a common idiom in the world of wine-food pairing. Intriguingly, the latest computational gastronomy research to contrast the relative impact of shared climate vs. geographical proximity suggests that proximity is the more important factor in terms of determining the similarity of various regional cuisines in China [99].

While much of the literature on computational gastronomy and flavour pairing has undoubtedly focused on the simultaneous delivery of flavours, it is worth noting how under the majority of everyday conditions (e.g. when several different elements are presented on the plate or when food is combined with a drink such as wine), one could well imagine how tasting experiences are more likely to occur sequentially. Hence, before closing, it is worth returning to the sequencing of flavour sensations.

\section{Sequencing flavour experiences}

While much of the discourse around pairing flavours seems to be premised on the simultaneous tasting of, e.g. food and wine, in practice, it is presumably more often the case that tasting experiences occur sequentially. The question then becomes one of whether one order of tasting is better than another and what factors influence the temporal ordering of our tasting experiences. We started this article thinking about sequential flavour experiences in one of Denis Martin's dishes. However, there are a number of factors that can influence the experienced order of tastes that are worth mentioning briefly before closing.

\section{Layering tasting sensations}

One might think here about the layers of lettuce, cheese, bacon, etc. in a burger. Indeed, some researchers have already put their mind to optimizing the layering of the elements in this most popular of foods (e.g. [100, 101]; though see [102]). One might also consider how most icecream sundaes, individually served trifles, etc. encourage the dinner into experiencing the elements in the dish in a certain sequence. 9 In fact, the layering and orientation of various foods can also be seen as highlighting the contrast between what pleases the eye and what might be expected to please the palate. Layering has also become interesting to the food industry as a way of asymmetrically distributing certain ingredients (e.g. salt) in order to enhance the perception of this quality in the food.

For instance, most chocolate McVitie's biscuits have the chocolate on the "bottom" of the biscuit. The plain biscuit side is what they consider the "top" (see [103]). However, if you watch how people actually eat their biscuits, it would appear that the majority eat them with the chocolate side facing up. Perhaps, people want to see the chocolate as they eat the biscuit (appealing to the eye; see [16]), even though, given the distribution of receptors in the oral cavity, it could be argued that a better tasting experience would be had were the biscuit to be eaten in the "proper" orientation (i.e. with the chocolate side facing downward). Here, it should be stressed that we do not yet have any evidence to support the argument regarding the initial orientation of the biscuit in the mouth. Nevertheless, related work from the food industry has stressed the importance of the initial tasting experience, given the assumption of homogeneity (of a given food product), across a particular tasting experience (e.g. see [104-107]).

Sushi provides another interesting example here. For according to tradition, it is the fish that should be dipped into the soy sauce (in the cases where the chef deems it ok to dip in soy sauce). Next, the sushi should be inserted into the mouth fish-side-down, so that the diner experiences the flavours of the fish/soy sauce more directly on their tongue (see [108]). ${ }^{10}$ Once again, though, presenting the sushi fish side down would not be very attractive, as all you would see is white rice (i.e. the variety between different sushi would be obscured). There is something here about signalling choice visually and perhaps putting the most expensive or freshest ingredients on top.

Taken together, then, these examples of layered tasting experiences help to highlight, once again, the tension between serving a food so that it appeals maximally to the eye and serving it so that it delivers the optimal multisensory tasting experience.

\section{The role of attention in individuating and binding together the components of flavour}

Sometimes, changing the sequence in which mouth sensations are delivered/experienced does nothing more than that. Think about it, if a light is seen before a sound is heard, it will be perceived in much the same way as if the sound is perceived before the light. That is, the perception of the component stimuli remains unchanged; all that seems to change is the perception of the temporal relationship between them. ${ }^{11}$ When it comes to the chemical senses, though, a reading of some of the older literature might be taken to suggest that things may, at least sometimes, be importantly different. For, as reported by Georg von Békésy [109], when an olfactory stimulus was delivered shortly before a gustatory stimulus, the ensuing mixture was typically experienced as an odour. However, when the temporal order of stimulation 
was reversed by the order of a few milliseconds, the experience was of a taste localized to the mouth instead (due, presumably, to the phenomenon of oral referral; see [110], for a review).

This degree of precise temporal control of stimulus delivery most likely lies beyond the influence of the chef. Nevertheless, what is important to the diner's tasting experience, at least at the fine temporal scale (i.e. in the millisecond range), is attention. What the diner voluntarily chooses to attend to can bias, and even reverse, the order in which stimuli are perceived (e.g. see [111], for a review of the literature on prior entry; cf. [112]). ${ }^{12}$ Here, it is worth noting that even the very description of the elements in a dish may help direct the diner's attention in a certain way during a tasting experience. Hence, it can be argued that attention needs to be considered as an important factor when it comes to any consideration of sequential tasting experiences taking place in the timescales of seconds [113]. Furthermore, the attentional disposition of the taster, specifically whether they choose to take an analytic vs. synthetic approach to tasting, has also been shown to play an important role in people's response to food stimuli (e.g. see [114]).

Here, though, it is important to bear in mind that the published research also suggests that people can find it very difficult to pick apart (or individuate) and attend to the individual components of flavour stimuli because of the brain's tendency to group the component inputs into a perceptual gestalt $[115,116]$. Binding the component stimuli in this way (i.e. as a multisensory flavour gestalt) may well limit the ability of a taster to direct their attention selectively to just one element in a complex tasting experience (see [111]). The laboratory research clearly suggests that people exposed to odour mixtures really struggle to identify any more than three odours in mixtures (of up to six odorants, say) even if they are familiar with all of the component odours $[115,117,118] .{ }^{13}$ Furthermore, as pointed out by Stevenson [113], the exogenous attention capture by gustatory and oral-somatosensory stimuli in the oral cavity may be a key part of the reason why people find it so difficult to attention selectively to the olfactory component of a flavour stimulus, much though they might wish to do so (see also [119]).

In summary, therefore, the oft-mentioned limitations in the ability of people to direct their attention to separate components of a simultaneously experienced flavour may well be part of the reason why the sequential delivery of tasting experiences might be preferred as a method of delivery for the chef. Furthermore, the sequential delivery of tasting experiences also offers the opportunity for hedonic escalation (see [9]). This is the name given to the increased liking of each additional bite of a palatable food. As Crolic and Janiszewski point out in their recent paper, hedonic escalation is more likely to occur when a palatable food consists of a complex combination of flavours. It is also more likely to occur when someone is motivated to taste additional flavours on each successive bite. To us, the latter description sounds very much like the mindset of the typical diner eating in a modernist restaurant these days. As Crolic and Janiszewski put it: "...hedonic escalation is more prevalent when people can identify more flavors, attend to additional flavors on each taste trial, have an opportunity to identify an additional flavor on each taste trial, and isolate distinct flavors on each taste trial."

Thus, given the limited ability of diners to attend selectively to the elements in a simultaneously experienced flavour (due to gestalt grouping and exogenous attentional capture by the mouth), and given the existence of the phenomenon of hedonic escalation [9], especially amongst many contemporary diners, the question in which order will tasting experiences deliver maximum palatability/pleasure becomes more important than ever. That said, the mystery still remains as to the conditions under which all components of a flavour experience will bind together into a multisensory gestalt, and when they remain distinctive, as in the dishes served by Denis Martin and Heston Blumenthal that we started with. One might wonder whether these, then, are quintessential examples of hedonic escalation but delivered in a single mouthful.

\section{Conclusions}

The order and sequence in which people taste foods (and drinks) matters more than many of us realize. ${ }^{14}$ In this review, we started out by highlighting the potential tension that exists between artistic plating-what looks good to the eye [13, 14] —and the likely sequence in which diner will sample/experience the elements on the plate. We examined the literature concerning the principles of pairing, combining, and sequencing tasting experiences. We highlighted examples (of both good and bad pairing) reflecting chemical interactions taking place between the component stimuli, giving rise to a resulting tasting experience that itself may be much better/worse than predicted from the mere sum of the parts. We also summarized those cases where eating something changes the functioning of the receptors in the mouth (think globe artichoke, miracle fruit, Szechuan peppercorn, etc.). ${ }^{15}$

Having looked at these more extreme examples of the way in which physico-chemical interactions can influence sequential tasting, we then outlined some of the psychological factors relevant to sequencing flavour experiences, such as dynamic contrast and hedonic escalation. We highlighted some of the attentional limitations associated with trying to attend separately to the 
components of complex flavour experiences. Further, we contrasted that with the hedonic escalation that is sometimes seen when flavours are experienced (and attended to) sequentially. Of course, while different flavours may, on occasion, be experienced simultaneously (this being the situation that much of the flavour pairing literature talks about), the more common situation under everyday consumption conditions is the sequential experiencing of the elements in a dish or when combining food and drink. As this review has tried to make clear, a number of factors may influence the likely success (or failure) of sequential tasting experiences.

That said, the majority of the literature on combining flavours tends to focus on simultaneous flavour pairing. As such, we reviewed some of the general principles of flavour matching that have been suggested in the literature. These included the following: similarity-that is, matching components based on common flavour compounds (or similar flavour profiles); contrast-combinations that are purposely chosen because they differ from each other (a strategy that, as we have seen, is more common in the cuisines of some countries than others); and synergy (or emergence)-those combinations that together deliver new flavour experiences (see [90]) or else harmonize with one another.

However, beyond these perceptual approaches to pairing, we also came across examples of conceptual pairing (i.e. based on tradition or by region), as well as examples of individual pairing (based on an individual's own personal preferences, experiences, and food history/culture; [53]). Indeed, the latest research shows culture can also exert an influence, both on the particular combinations of ingredients an individual becomes familiar with (through prior exposure) and through the underlying principle of either picking harmonizing (Western cuisine) or distinctive elements (as in Indian cuisine; [84]; see also [67, 78]).

There can be little doubting that the concept of flavour pairing (based on shared chemical composition) and the rapidly emerging field of computational gastronomy have become increasingly popular in recent years as possible routes to the effective combination of flavours (that are not normally found together). However, as the limited research makes clear, there are a number of problems and limitations with this approach that mean that its main use may be in terms of fostering creativity in the kitchen rather than necessarily predicting unusual flavour combinations that will work well together. As such, we would argue that the effective combination of novel elements in a dish or in a food/drink combination still remains as much an art as a science.

In closing, then, let us return to the question with which we started this piece: Does the order in which chemical sensations are experienced when tasting a dish matter? Given that as a number of the examples reviewed here show it often does, then we would argue that a more careful analysis of how diners typically interact with the food on their plate (i.e. do they start at the side, or in middle, with the food on the left, or the right, etc.) becomes increasingly relevant in terms of designing the optimal plating arrangements. Optimality, here, being defined in terms both of what is good for the eyes of the diner and also for their palate. ${ }^{16}$

And looking to the future, while in this review, the focus has been squarely on what is going on within a mouthful or a single dish. One can, of course, broaden things out to consider the temporal sequencing of the courses within a meal, say, or the meals within a day (e.g. [8, 120-123]). However, addressing that issue is definitely the subject for another day.

\section{Endnotes}

${ }^{1}$ A somewhat similar approach can be used to resolving the tannins in a young red wine by first chewing on a coffee bean. The latter also contains tannin [124], and so the tannic wine will not be perceived as being quite so astringent as it otherwise might (this a trick introduced by Prof. Barry Smith).

${ }^{2}$ Chartier's [17] Taste buds and molecules was perhaps the first book to really discuss food-wine pairing at the molecular level. According to Chartier, wine/food pairings are akin to note-by-note cooking in that he believes pairings can be made between the two at the molecular level. However, while Chartier's book is packed with apparently successful food-wine pairings, and the approach has been enthusiastically endorsed by Ferran Adrià and Juli Soller of elBulli fame, the text itself is short on detail about how exactly such molecular matches are established.

${ }^{3}$ This is not quite all though; while Chef Watson does access a database of recipes containing tens of thousands of existing dishes, this information is then connected with a second database that provides information concerning the flavour compounds in thousands of ingredients. Chef Watson also has information about how people respond to different combinations of flavours (see [125]).

${ }^{4}$ In fact, it turns out that strawberries have more in common with white wine than they do with apples, oranges, or honey (see [80]). Scientific American produced a great interactive graphic a couple of years ago that allows one to see how many flavour compounds are shared by different ingredients (see http://www.scientificamerican.com/article/flavor-connection-taste-map-interactive/).

${ }^{5}$ This all sounds simple enough if you believe the claim that "pleasantness is an approximately linear property of compounds [126]. If two compounds are mixed together and smelled, the hypothesis is that the odor pleasantness of the mixture is approximately a linear combination of the pleasantness values of the individual compounds. With such linearity, one can predict the pleasantness of 
food ingredients that contain several flavour compounds and of dishes that in turn contain several ingredients." (Quoted in Varshney et al., [75], p. 10). Hold on for a moment, though. What about dried scallops and red wine? Two flavours that many people like individually but together do not combine well. Strawberry aroma and chicken stock aroma? Perhaps, this prediction about pairing works better for unknown aromas and/or odours that are unrelated to food? Or maybe this claim holds more as a generalization despite there being a number of exceptions.

${ }^{6}$ This despite the huge success of companies such as Flavour Pairing (see https://www.foodpairing.com/; https://www.foodpairing.com/en/home), whose poster is to be found on the walls of many a top restaurant kitchen.

${ }^{7}$ Just take the following quote from Ahnert ([67], p. 2): "By comparing the network of ingredients to a body of 56,498 online recipes, downloaded from epicurious.com, allrecipes.com, and menupan.com, we were able to show this hypothesis is confirmed in most Western cuisines, but not in Eastern ones. This result indicates that shared compounds may offer one of several possible mechanisms that can make two ingredients compatible."

${ }^{8}$ Here, one might wonder whether what grows together also tends to share more chemical compounds than might be expected by chance.

${ }^{9}$ And while we have focused on the temporal order of sensations during a mouthful or dish, it is worth noting that there are also interesting questions to be addressed about the temporal ordering of sensations across the different courses in a meal, say [121, 122]. Unfortunately, however, addressing this intriguing topic lies well beyond the scope of the present article.

${ }^{10}$ It is considered wrong to dip the rice part of the sushi in soy sauce (as most Westerners intuitively seem to do), as the rice would soak up too such sauce and may disintegrate.

${ }^{11}$ That said, there are a few exceptions: Thunder before lightning would likely be characterized as two separate events, whereas in the reverse order, it may well be treated as a single event.

${ }^{12}$ There is also an intriguing link to the awareness of mouthfeel characteristics here too, as part of the total tasting experience (see $[127,128]$ ). Remember that in the sequentially experienced dish from Denis Martin that we started this piece with, there was an initial wasabi hit, likely localized to the bridge of the nose, followed by the taste/texture/flavour of the tuna, and ending up with the lingering creamy mouthfeel of the white chocolate tablet.

${ }^{13}$ This finding, by itself, might nudge the chef toward trying to deliver different flavours sequentially rather than all at the same time.

${ }^{14}$ The Japanese were onto this long ago. Just take the following quote: "Kaiseki meals usually start with the most delicate and subtle of flavors and textures, such as a few slices of raw sashimi. This is followed by soup or simmered vegetables in broth. The flavors and textures then get progressively more substantial; perhaps some crispy tempura, followed by grilled fish or meat. The meal then winds down with rice, soup and pickles. Dessert is sometimes served as well, and is always light; a perfect slice of melon, or perhaps a refreshing cold tofu custard." (quoted at http://www.savoryjapan.com/learn/ culture/power.of.five.html).

${ }^{15}$ Olfactory and gustatory adaptation effects can be thought of operating along much the same lines.

${ }^{16}$ One intriguing culinary challenge here, then, is to try and find a combination of elements that individually taste just fine and in combination taste much better in one order than another.

\section{Acknowledgements \\ None. \\ Funding \\ CS would like to acknowledge the AHRC Rethinking the Senses grant (AH/L007053/1).}

Availability of data and materials

There is no data or material to make available.

Authors' contributions

CS, Q(J)W, and JZ wrote all parts of this review. All authors read and approved the final manuscript.

\section{Authors' information}

Charles Spence is an experimental psychologist and gastrophysicist working out of Oxford University who is fascinated by the design of multisensory dining experiences. In 2014, he published the prize-winning The perfect meal: The multisensory science of food and dining (Oxford, UK: Wiley-Blackwell) together with Dr. Betina Piqueras-Fiszman. In March, 2017, he will publish his latest book, Gastrophysics: The new science of eating, with Penguin.

Qian (Janice) Wang is a PhD student currently completing her PhD at the Crossmodal Research Laboratory, Oxford University. She is also the captain of the Oxford University Blind Wine tasting team.

Jozef Youssef is a professional chef and director of Kitchen Theory. In 2013, he published Molecular cooking at home: Taking culinary physics out of the lab and into your kitchen with Quintet Publishing.

Competing interests

The authors declare that they have no competing interests.

Consent for publication

Approval to publish has been given where required.

Ethics approval and consent to participate

No participants were tested in this review paper/opinion piece.

\section{Author details}

${ }^{1}$ Department of Experimental Psychology, University of Oxford, Oxford OX1 3UD, UK. ${ }^{2}$ Kitchen Theory, London, UK.

Received: 20 October 2016 Accepted: 7 January 2017

Published online: 07 March 2017

\section{References}

1. Martin D. Évolution. Lausanne: Editions Favre; 2007

2. Halpern BP. More than meets the tongue: Temporal characteristics of taste intensity and quality. In: Lawless HT, editor. Sensory science theory and applications in foods. New York, NY: Marcel Dekker; 1991. p. 37-105. 
3. Jinks A, Laing DG. Temporal processing reveals a mechanism for limiting the capacity of humans to analyze mixtures. Cogn Brain Res. 1999;8:311-25.

4. Kobayakawa T, Gotow N. Interaction between olfaction and gustation by using synchrony perception task. i-Perception. 2011;2(8). http://i-perception. perceptionweb.com/journal///article/ic964.

5. Kuznicki JT, Turner LS. Temporal dissociation of taste mixture components. Chem Senses. 1988;13:45-62

6. Marshall K, Laing DG, Jinks AL, Effendy J, Hutchinson I. Perception of temporal order and the identification of components in taste mixtures. Physiol Behav. 2005;83:673-81.

7. Blumenthal H. Weird but wonderful. In: The Guardian, May $4^{\text {th }} .2002$. p. 84. https://www.theguardian.com/lifeandstyle/2002/may/04/foodanddrink. shopping.

8. Hyde RJ, Witherly SA. Dynamic contrast: A sensory contribution to palatability. Appetite. 1993;21:1-16.

9. Crolic C, Janiszewski C. (in press). Hedonic escalation: When food just tastes better and better. J Consumer Res.

10. Myhrvold N, Young C. Modernist cuisine. The art and science of cooking. La Vergne, TN: Ingram Publisher Services; 2011.

11. Youssef J. Molecular cooking at home: Taking culinary physics out of the lab and into your kitchen. London, UK: Quintet Publishing; 2013.

12. Aduriz AL. Mugaritz: A natural science of cooking. New York, NY: Phaidon; 2014.

13. Apicius. Cooking and dining in Imperial Rome (c. $1^{\text {st }}$ Century; translated by J. D. Vehling). Chicago, IL: University of Chicago Press; 1936.

14. Michel C, Velasco C, Gatti E, Spence C. A taste of Kandinsky: Assessing the influence of the artistic visual presentation of food on the dining experience. Flavour. 2014;3:7.

15. Deroy $\mathrm{O}$, Michel $\mathrm{C}$, Piqueras-Fiszman $B$, Spence $C$. The plating manifesto (I): From decoration to creation. Flavour. 2014:3:6.

16. Spence C, Okajima K, Cheok AD, Petit O, Michel C. Eating with our eyes: From visual hunger to digital satiation. Brain \& Cognition. 2016;110:53-63.

17. Chartier F. Taste buds and molecules: The art and science of food, wine, and flavor (translated by Levi Reiss). Hoboken, NJ: John Wiley and Sons; 2012.

18. De Klepper M. Food pairing theory: A European fad. Gastronomica: J Food Culture. 2011:11:55-8.

19. Cooper D. Wine with food. 2. In: Wine with food. London, UK: Octopus Publishing; 1980. p. 10-9.

20. Simon J. Rules, \& how to break them. In: Wine with food. London, UK: Octopus Publishing; 1996. p. 10-9.

21. Tamura T, Taniguchi K, Suzuki Y, Okubo T, Takata R, Konno T. Iron is an essential cause of fishy aftertaste formation in wine and seafood pairing. J Agric Food Chem. 2009;57:8550-6.

22. Ribéreau-Gayon P, Glories Y, Maujean A, Dubordieu D. Chapter 4: Dry extract and minerals. In: Handbook of enology, The chemistry of wine stabilization and treatments, vol. 2. 2nd ed. West Sussex, UK: Wiley; 2006. p. 91-108.

23. Jackson S. Wine, health, and food. In: Wine science: Principles, practice, perception. 2nd ed. San Diego, CA: Academic Press; 2000. p. 600-5.

24. Walton S, Glover B. Drinking wine with food. In: The ultimate encyclopedia of wine, beer, spirits \& liqueurs. London, UK: Lorenz Book; 1998. p. 21.

25. Greenwood V. How to hack your taste buds. In: BBC, December $15^{\text {th }} .2014$ http://www.bbc.com/future/story/20141214-how-to-hack-your-taste-buds.

26. Woollaston V. So THAT'S why toothpaste ruins the taste of food! Chemicals in paste destroy receptors on the tongue and cause a bitter sensation. In: Daily Mail Online, October $7^{\text {th }}$. 2014. http://www.dailymail.co.uk/ sciencetech/article-2783404/So-THAT-s-toothpaste-ruins-taste-foodChemicals-paste-destroy-receptors-tongue-cause-bitter-sensation.html.

27. Lawless HT. Sensory interaction in mixtures. J Sensory Stud. 1986;1:259-74.

28. Lawless HT, Stevens DA. Effects of oral chemical irritation on taste. Physiol Behav. 1984;32:995-8.

29. Daniell WF. On the Synsepalum dulcificum, de Cand; or miraculous berry of western Africa. Pharmacol J. 1852;11, 445-448.

30. Anon. Gymnema sylvestre, an Indian plant which, when chewed, destroys the power of tasting sugar. Pharmacol J. 1847;7:351-2.

31. Eisner T, Halpern BP. Taste distortion and plant palatability. Science. 1971; 172:1362.

32. Kurihara K, Beidler LM. Taste-modifying protein from miracle fruit. Science. 1968;161:1241-3.

33. Koizumi A, Tsuchiya A, Nakajima Kl, Ito K, Terada T, Shimizu-lbuka A, Briand L, Asakura T, Misaka T, Abe K. Human sweet taste receptor mediates acidinduced sweetness of miraculin. Proc Natl Acad Sci U S A. 2011;108:16819-24.
34. Spence C, Piqueras-Fiszman B. The perfect meal: The multisensory science of food and dining. Oxford, UK: Wiley-Blackwell; 2014.

35. Hagura N, Barber H, Haggard P. Food vibrations: Asian spice sets lips trembling. Proc R Soc B. 2013;280:20131680.

36. Bartoshuk LM, Lee CH, Scarpellino R. Sweet taste of water induced by artichoke (Cynara scolymus). Science. 1972;178:988-90.

37. Blakeslees AF. A dinner demonstration of threshold differences in taste and smell. Science. 1935;81:504-7.

38. Woods WM. Artichokes. Science. 1971;193:1195.

39. Beard J. Gourmet. 1971:31:30.

40. Centelles F. Can wine and artichokes ever be friends? May $4^{\text {th }}$. 2014. www. jancisrobinson.com.

41. Graves E. Life. 1967:62:114

42. Cometto-Muñiz JE, Cain WS. Olfactory adaptation. In: Doty RL, editor. Handbook of olfaction and gustation. New York: Dekker; 1995. p. 257-81.

43. McBurney DH, Pfaffmann C. Gustatory adaptation to saliva and sodium chloride. J Exp Psychol. 1963:65:523-9.

44. O'Mahoney M, Heintz C. Direct magnitude estimation of salt taste intensity with continuous correction for salivary adaptation. Chem Senses. 1981;6: 101-12.

45. Blumenthal H. The big Fat Duck cookbook. London, UK: Bloomsbury; 2008.

46. Nygren IT, Gustafsson IB, Johansson L. Perceived flavour change in blue mould cheese after tasting white wine. Food Service Technol. 2003b;3: 143150.

47. Schifferstein HNJ, Frijters JER. Contextual and sequential effects on judgments of sweetness intensity. Percept Psychophys. 1992;52:243-55.

48. Galmarini M. Use of temporal dominance of sensations (TDS) to better understand wine-cheese associations. Paper presented at Eurosense 2016, 11-14 ${ }^{\text {th }}$ September. Dijon, France; 2016.

49. Galmarini MV, Loiseau A-L, Visalli M, Schlich P. Use of multi-intake Temporal Dominance of Sensations (TDS) to evaluate the influence of cheese on wine perception. J Food Sci. 2016:81:S2566-77.

50. Madrigal-Galan B, Heymann $\mathrm{H}$. Sensory effects of consuming cheese prior to evaluating red wine flavour. Am J Enology Viticulture. 2006:57:12-22.

51. Nygren IT, Gustafsson IB, Johansson L. Perceived flavour changes in white wine after tasting blue mould cheese. Food Service Technol. 2002;2:163-71.

52. Nygren IT, Gustafsson IB, Johansson L. Effects of tasting technique sequential tasting vs. mixed tasting - on perception of dry white wine and blue mould cheese. Food Service Technol. 2003a;3: 61-69.

53. Eschevins A. From beverage to companion food: Experts' principles for pairing wines and beers with food. Paper presented at Eurosense 2016, 11$14^{\text {th }}$ September. Dijon, France; 2016.

54. Dornenburg A, Page K. What to drink with what you eat: The definitive guide to pairing food with wine, beer, spirits, coffee, tea - even water Based on expert advice from America's best sommeliers. USA: Little, Brown, \& Company; 2006

55. Page K, Dornenburg A. The flavor bible. 1st ed. USA: Little, Brown, \& Company; 2008

56. Segnit N. The flavour thesaurus: Pairings, recipes and ideas for the creative cook. London, UK: Bloomsbury; 2010.

57. Shepherd GM. Neurogastronomy: How the brain creates flavor and why it matters. New York, NY: Columbia University Press; 2012.

58. Blank DM, Mattes RD. Sugar and spice: Similarities and sensory attributes. Nurs Res. 1990;39:290-3.

59. Smith BC. Same compounds: Different flavours? In: Chassagne D, editor. Proceedings of Wine Active Compounds 2008. University of Bourgogne: Oenopluria Media; 2008. p. 98-102.

60. Schifferstein HNJ, Verlegh PWJ. The role of congruency and pleasantness in odor-induced taste enhancement. Acta Psychol (Amst). 1996:94:87-105.

61. Stevenson RJ, Boakes RA. Sweet and sour smells: Learned synaesthesia between the senses of taste and smell. In: Calvert GA, Spence C, Stein BE, editors. The handbook of multisensory processing. Cambridge, MA: MIT Press; 2004. p. 69-83.

62. Stevenson RJ, Prescott J, Boakes RA. The acquisition of taste properties by odors. Learning Motiv. 1995;26:433-55.

63. Williams JA, Bartoshuk LM, Fillingim RB, Dotson CD. Exploring ethnic differences in taste perception. Chem Senses. 2016;41:449-56.

64. Rozin E. Ethnic cuisine: The flavor-principle cookbook. Brattleboro, VT: The Stephen Greene Press; 1983.

65. Visser $M$. The rituals of dinner: The origins, evolution, eccentricities, and meaning of table manners. London, UK: Penguin Books; 1991. 
66. Ahn YY, Ahnert SE, Bagrow JP, Barabási AL. Flavor network and the principles of food pairing. Sci Rep. 2011;1(196):1-6.

67. Ahnert SE. Network analysis and data mining in food science: The emergence of computational gastronomy. Flavour. 2013;2:4.

68. Davis AP. Digital gastronomy: When an IBM algorithm cooks, things get complicated-and tasty. Wired. 2013;20(10). September $17^{\text {th }}$. https://www. wired.com/2013/09/digitalgastronomy/.

69. IBM in collaboration with Institute of Culinary Education. Cognitive cooking with Chef Watson: Recipes for innovation from IBM \& the Institute of Culinary Education. Institute of Culinary Education; 2015.

70. Kinouchi O, Diez-Garcia RW, Holanda AJ, Zambianchi P, Roque AC. The nonequilibrium nature of culinary evolution. New J Phys. 2008;10(7):073020.

71. Morris RG, Burton SH, Bodily PM, Ventura D. Soup over beans of pure joy: Culinary ruminations of an artificial chef. In: Proceedings of the International Conference on Computer Creativity (ICCC 2012), May 2012. 2012. p. 119-25.

72. Singel R. Google recipe search cooks up next gen of search. In: Wired, February, 24 ${ }^{\text {th }} .2011$. http://www.wired.com/epicenter/2011/02/googlerecipe-semantic/.

73. Taft DK. Cognitive cooking: Inside IBM's Watson food truck. In: eWeek, March $14^{\text {th }} .2014$. http://www.eweek.com/database/slideshows/cognitivecooking-inside-ibms-watson-food-truck.html.

74. Teng CY, Lin YR, Adamic LA. Recipe recommendation using ingredient networks. In: Proceedings of the $3^{\text {rd }}$ Annual ACM Web Sci. Conf. (WebSci'12), June 2012. 2012. p. 298-307. https://arxiv.org/pdf/1111.3919. pdf.

75. Varshney KR, Varshney LR, Wang J, Myers D. Flavor pairing in medieval European cuisine: A study in cooking with dirty data. In: Proceedings of the International Joint Conference on Artificial Intelligence Workshops. 2013. p. 3-12.

76. Varshney LR, Pinel F, Varshney KR, Bhattachrjya D, Schörgendorfer A, Chee YM. A big data approach to computational creativity. In: IEEE International Conference on Cognitive Informatics and Cognitive Computing, New York, July. 2013.

77. Burdock GA. Fenaroli's handbook of flavor ingredients. 6th ed. Boca Raton, FL: CRC Press; 2010.

78. Ahn YY, Ahnert SE. The flavor network. Leonardo. 2013;46:272-3.

79. Zolfaghifard E. Why Indian food is so delicious: Scientists say our love of curry is down to a lack of overlapping flavours. In: Daily Mail Online, March $4^{\text {th }}$. 2015. http://www.dailymail.co.uk/sciencetech/article-2979794/WhyIndian-food-delicious-Scientists-say-love-curry-lack-overlapping-flavours.html.

80. Ferdman RA. Scientists have figured out what makes Indian food so delicious. In: The Washington Post, March $3^{\text {rd }}$. 2015. https://www. washingtonpost.com/news/wonk/wp/2015/03/03/a-scientific-explanation-ofwhat-makes-indian-food-so-delicious/.

81. Blumenthal H. Naivety in the kitchen can lead to great inventions, but too much can take you to some strange places. In: The Times, August $19^{\text {th }}$. 2010. p. 45.

82. Kort M, Nijssen B, van Ingen-Visscher K, \& Donders J. (n.d.). Food pairing from the perspective of the 'volatile compunds in food' database (pp. 589592). https://home.zhaw.ch/yere/pdf/Teil146\%20\%20Expression\%20of\%20Multidisciplinary.pdfb.

83. Bredie WLP, Petersen MA, Hartvig D, Frøst MB, Risbo J, Møller P. Flavour pairing of foods: A physical-chemical and multisensory challenge for health promotion. Eur Sens Netw. 2015. http://www.esn-network.com/index. php?id $=1034$.

84. Jain A, Rakhi NK, Baglerb G. Spices form the basis of food pairing in Indian cuisine. 2015. http://arxiv.org/ftp/arxiv/papers/1502/1502.03815.pdf.

85. Mauer L, El-Sohemy A. Prevalence of cilantro (Coriandrum sativum) disliking among different ethnocultural groups. Flavour. 2012;1:8.

86. Wysocki CJ, Beauchamp GK. Ability to smell androstenone is genetically determined. Proc Natl Acad Sci U S A. 1984;81:4899-902.

87. Mottram D. How flavours develop and change during cooking. In: Blumenthal H, editor. The big Fat Duck cookbook. London, UK: Bloomsbury; 2008. p. 501-2.

88. Breslin PAS, Beauchamp GK. Salt enhances flavor by suppressing bitterness. Nature. 1997;387:563.

89. Keast RSJ, Breslin PAS. An overview of binary taste-taste interactions. Food Qual Preference. 2002;14:111-24.

90. Mitchell MJ, McBride RL. Effects of propanol masking odor on the olfactory intensity scaling of eugenol. J Exp Psychol. 1971;87:309-13.

91. Kruger L, Feldzamen AN, Miles WR. A scale for measuring supra-threshold olfactory intensity. Am J Psychol. 1955;68:117-23.
92. Nijssen LM, van Ingen-Visscher CA, Donders JJH. Food database - Version 13.2 - Zeist. The Netherlands: TNO Triskelion; 1963-2012.

93. Van Gemert LJ. Flavour threshold values in water and other media. 2nd ed. Canton, GA: Leffingwell; 2011.

94. Velasco C, Michel C, Youssef J, Gamez X, Cheok AD, Spence C. Colour-taste correspondences: Designing food experiences to meet expectations or to surprise. Int J Food Design. 2016;1:83-102.

95. Trout C. I trusted my gut to IBM's Watson and it gave me a fowl oldfashioned. In: Engadget, May 15 th .2015 . http://www.engadget.com/2015/ 05/15/drinking-with-watson/.

96. Dalal T. Tarla Dalal. 2014. http://www.tarladalal.com.

97. Schaal B, Durand K. The role of olfaction in human multisensory development. In: Bremner AJ, Lewkowicz D, Spence C, editors. Multisensory development. Oxford, UK: Oxford University Press; 2012. p. 29-62.

98. Schaal B, Marlier L, Soussignan R. Human foetuses learn odours from their pregnant mother's diet. Chem Senses. 2000;25:729-37.

99. Zhu YX, Huang J, Zhang ZK, Zhang QM, Zhou T, Ahn YY. Geography and similarity of regional cuisines in China. PLoS One. 2013;8(11):e79161.

100. Lee J. How to make the perfect burger: Oxford food scientist claims to have answer: Oxford University chef says perfect burger is $7 \mathrm{~cm}$ tall, should be eaten to music, given a name and should feel as good as it tastes. In: The Telegraph, August 16 ${ }^{\text {th }} .2015$. http://www.telegraph.co.uk/news/science/ science-news/11823677/How-to-make-the-perfect-burger-Oxford-foodscientist-claims-to-have-answer.html.

101. Morgan M. A 7cm wide patty, crunchy lettuce and a warm bun... eaten with your hands: Chef reveals formula for the perfect burger (and how it SOUNDS is as important as the taste). In: Daily Mail Online, August $25^{\text {th }}$. 2015. http://www.dailymail.co.uk/femail/food/article-3210117/Chef-revealsformula-perfect-burger-SOUNDS-just-important-taste.html.

102. Sinnerton J. Burger battle: Boffins can kiss my buns. In: Brisbane CourierMail, August $5^{\text {th }}$. 2015. http://www.couriermail.com.au/news/queensland/isthis-queenslands-best-burger-ohio-cafe-owner-yogesh-koshe-reckons-hisrecipe-cant-be-beat/story-fnihsrf2-1227514375022.

103. Enoch N. Crumbs, we've been eating McVitie's Digestives and Hobnobs all wrong! Firm says chocolate part is the BOTTOM. In: Daily Mail Online, March $28^{\text {th }} .2014$. http://www.dailymail.co.uk/news/article-2591803/McVitiesDigestive-Hobnobs-shock-Weve-eating-wrong-way.html\#ixzz4KIw1L5e5.

104. Dijksterhuis GB, Le Berre E, Woods AT. Food products with improved taste. In: Patent Identifier No. EP2451289 A1. 2010

105. Dijksterhuis G, Boucon C, Le Berre E. Increasing saltiness perception through perceptual constancy created by expectation. Food Qual Preference. 2014; 34:24-8.

106. Le Berre E, Boucon C, Knoop M, Dijksterhuis G. Reducing bitter taste through perceptual constancy created by an expectation. Food Qual Preference. 2013;28:370-4.

107. Woods AT, Poliakoff E, Lloyd DM, Dijksterhuis GB, Thomas A. Flavor expectation: The effects of assuming homogeneity on drink perception. Chemosensory Perception. 2010;3:174-81.

108. Lowry D. The connoisseur's guide to sushi: Everything you need to know about sushi varieties and accompaniments, etiquette and dining tips and more. Boston, MA: Harvard Common Press; 2005.

109. von Békésy G. Interaction of paired sensory stimuli and conduction in peripheral nerves. J Appl Physiol. 1963;18:1276-84.

110. Spence C. Oral referral: Mislocalizing odours to the mouth. Food Qual Preference. 2016;50:117-28.

111. Spence C, Parise C. Prior entry. Consciousness Cognition. 2010;19:364-79.

112. Ashkenazi A, Marks LE. Effect of endogenous attention on detection of weak gustatory and olfactory flavors. Percept Psychophys. 2004;66:596-608.

113. Stevenson RJ. The role of attention in flavour perception. Flavour. 2012;1:2.

114. Prescott J, Lee SM, Kim KO. Analytic approaches to evaluation modify hedonic responses. Food Qual Preference. 2011;22:391-3.

115. Laing DG, Link C, Jinks AL, Hutchinson I. The limited capacity of humans to identify the components of taste mixtures and taste-odour mixtures. Perception. 2002;31:617-35.

116. Spence C. Cross-modal perceptual organization. In: Wagemans J, editor. The Oxford handbook of perceptual organization. Oxford, UK: Oxford University Press; 2015. p. 649-64.

117. Laing D, Francis G. The capacity of humans to identify odors in mixtures. Physiol Behav. 1989;46:809-14.

118. Laing DG, Glenmarec A. Selective attention and the perceptual analysis of odor mixtures. Physiol Behav. 1992;52:1047-53. 
119. Stevenson RJ, Mahmut MK, Oaten MJ. The role of attention in the localization of odors to the mouth. Atten Percept Psychophys. 2011;73:247-58.

120. Lahne J, Zellner DA. The great is the enemy of the good: Hedonic contrast in a coursed meal. Food Qual Preference. 2015;45:70-4.

121. Rolls BJ, Laster $L$, Summerfelt A. Meal order reversal: Effects of eating a sweet course first or last. Appetite. 1991;16:141-8.

122. Shukla AP, lliescu RG, Thomas CE, Aronne LJ. Food order has a significant impact on postprandial glucose and insulin levels. Diabetes Care. 2015;38(7): e98-9.

123. Spence, C., Wang, Q. (J.), \& Youssef, J. (2017). On the temporal structuring of the meal. Manuscript in preparation.

124. Savolainen H. Tannin content of tea and coffee. J Appl Toxicol. 1992;12:1912.

125. Wakefield J. What would a computer cook for dinner? BBC News Online March $7^{\text {th }} .2014$. http://www.bbc.co.uk/news/technology-26352743.

126. Lapid H, Harel D, Sobel N. Prediction models for the pleasantness of binary mixtures in olfaction. Chem Senses. 2008;33:599-609.

127. Gallace A, Spence $C$. In touch with the future: The sense of touch from cognitive neuroscience to virtual reality. Oxford, UK: Oxford University Press; 2014.

128. Haggard P, de Boer L. Oral somatosensory awareness. Neurosci Biobehavioural Rev. 2014;47:469-84.

\section{Submit your next manuscript to BioMed Central and we will help you at every step:}

- We accept pre-submission inquiries

- Our selector tool helps you to find the most relevant journal

- We provide round the clock customer support

- Convenient online submission

- Thorough peer review

- Inclusion in PubMed and all major indexing services

- Maximum visibility for your research

Submit your manuscript at www.biomedcentral.com/submit 